\title{
What Mathematics Education May Prepare Students for the Society of the Future?
}

\author{
Koeno Gravemeijer ${ }^{1}$ - Michelle Stephan ${ }^{2}$ (D) \\ Cyril Julie $^{3}$ - Fou-Lai Lin ${ }^{4}$ Minoru Ohtani ${ }^{5}$
}

Received: 20 October 2016 / Accepted: 3 February 2017 /Published online: 8 April 2017

(C) The Author(s) 2017. This article is published with open access at Springerlink.com

\begin{abstract}
This paper attempts to engage the field in a discussion about what mathematics is needed for students to engage in society, especially with an increase in technology and digitalization. In this respect, mathematics holds a special place in STEM as machines do most of the calculations that students are taught in K-12. We raise questions about what mathematical proficiency means in today's world and what shifts need to be made in both content and pedagogy to prepare students for $21 \mathrm{st}$ Century Skills and mathematical reasoning.
\end{abstract}

Keywords 21 st century skills · Digitalization · Mathematics education · Workplace mathematics

With this paper, we want to stimulate a discussion about what mathematics education should aim for in preparing students for the digital age. To illuminate the need for such a discussion, we will explore potential answers to the question, "What are the implications of the computerization and globalization of our society for mathematics education?" In doing so, we will build on the preparation for, and the deliberations of, the Discussion Group on this topic at the International Congress on Mathematics Education (ICME-13)

\section{Koeno Gravemeijer}

koeno@gravemeijer.nl

Michelle Stephan

Michelle.stephan@uncc.edu

1 Eindhoven University of Technology, Eindhoven, Netherlands

2 University of North Carolina, Charlotte, USA

3 University of the Western Cape, Cape Town, South Africa

4 National Taiwan Normal University, Taipei, Taiwan

5 Kanazawa University, Kanazawa, Japan 
in Hamburg, Germany. Although we recognize, as do others, that mathematics education for the future should be considered within the context of STEM education (English, 2015), in our view, mathematics deserves focused attention. This is especially true because of the way computerization affects mathematics and vice versa. Moreover, applications of mathematics also concern a variety of non-STEM fields, such as social sciences, finance, logistics, and risk analysis. In addition, we argue that mathematics education asks for careful vertical planning which might be compromised in a heavy push for STEM integration. In relation to this, we may observe that proponents of research focusing on what STEM integration might look like, such as English (2016), caution that current literature underemphasizes mathematics in the STEM world.

The motivation for our exploration is in the observation that the role of mathematics in our society is not only growing, but that mathematics is also increasingly done by machines. This will have an impact on both future job requirements and on the mathematics one will need to understand one's world. So the question arises, "How can mathematics education prepare students for being able to participate in the digital society of the future?"

Our world is changing rapidly under the influence of informatization, automatization, digitalization, and globalization. Computers are becoming cheaper and more powerful, steadily following Moore's Law: Every two years the number of transistors in a computer chip doubles (Moore, 1965). Brynjolfsson and McAfee (2014) add that not only microchip density but also processing speed, memory capacity, energy efficiency, and download speed develop with exponential speed. Moreover, almost everything is being digitized, transforming all sorts of information into ones and zeroes: text, sound, photos, videos, sensor output, and so forth. This allows for miniaturization, and as a consequence, all sorts of apparatus become smaller and cheaper. According to Brynjolfsson and McAfee (2014), a variety of new combinations will emerge in the near future as illustrated by the Google car,

[which] contains sixty-four separate laser beams and an equal number of detectors, all 545 mounted in a housing that rotates ten times a second. It generates about 1.3 million data points per second, which can be assembled by onboard computers into a real-time 3D picture extending one hundred meters in all directions. (Brynjolfsson \& McAfee, 2014, p. 55)

They go on to say that in 2000 a similar system would have cost about 35 million dollars, in 2013 about 80 thousand dollars. As consequence of this development, numerous jobs are, and will be, taken over by computers. Frey and Osborne (2013) estimate that $47 \%$ of total US workers run a high risk that their job will be automated in the foreseeable future. Especially routine tasks can easily be computerized. On the basis of a study on how the occupational distribution and the nature of work are changing over the period 1960-2009, Levy and Murnane (2012) found there is a growing demand of employees who possess complex communication and expert thinking skills, while the demand for (manual and cognitive) routine skills declines. At the same time, however, computers create new jobs since computers can also augment people's activity. But those new jobs require skills that are different from what was adequate for the old jobs. Education therefore will have to play a crucial role. These developments ask for a shift away from competencies that compete with what computers can do towards competencies that complement computer capabilities. 
Looking at the role of mathematics in the digital society, we may observe that mathematics is both pervasive and invisible. The role of mathematics grows together with the role of technology, as mathematics is at the core of what computers do. At the same time, the omnipresent mathematics is mainly hidden in all sorts of apparatus, which function as black boxes for its users. This leads to the apparent paradox that, in spite of the central role of mathematics in our society, we do not see mathematics and only few people seem to do mathematics. We might add that, today, basically all mathematical operations that are taught in primary, secondary, and tertiary education can be performed by computers and are performed by computers in the world outside school. This reveals a tension between what is going on in society and what is going on in schools. Or as Conrad Wolfram (2014) puts it, "In the real world we use computers for calculating, almost universally. In education we use people for calculating, almost universally" (p. 1). This does not mean that there is no need any more for learning mathematics, but what mathematics is important to learn changes. This may be illustrated with Keeler and Grandine's (2013) description of the work of about 60 mathematicians who are employed at the Applied Mathematics Group of Boeing: "In school the professor formulates the [mathematical] problem and you solve it-you hope. In industry, you formulate the [mathematical] problem and the software solves it-you hope" (p. 41). In this respect, we may re-emphasize our earlier remark that we have to shift away from teaching competencies that compete with what computers can do and start focusing on competencies that complement computer capabilities.

In this article, we start by investigating what changes are taking place in the world around us as a consequence of digitalization and globalization (Friedman, 2005). Next, we will explore what this might mean for the goals of mathematics education for the future. Given its prominence in the public discourse on education for the future, we will start by discussing the so-called 21 st century skills, which might be pursued in mathematics education. Next, we will turn to mathematics-specific goals, where we will try to chart the demands of the twenty-first century from the perspective of work and employability. Here, we will first focus on how the character of mathematics at the workplace differs from school mathematics. Then, we will explore the competencies that are at stake, taking as our starting point in an analysis of mathematical activity in a setting where computers do the mathematical calculations. We will complement this with an inventory of mathematical topics that deserve more attention given the progressive role they are playing in society. This will be complemented with a brief discussion of mathematics for everyday life in the context of the digital age. In closing, we summarize potential answers to the question, "What are the implications of the computerization and globalization of our society for mathematics education?", in the form of a list of propositions that are meant to spark this discussion on this issue.

\section{1st Century Skills}

Recently, many organizations and educators have argued that students must develop 21 st century skills to be effective post-education. The term 21 st century skills originate from the 21st Century Skills Project (Partnership for 21st century skills, 2015) with many projects following suit. A review study of a series of such projects by Voogt and Pareja (2010) shows that they come to similar lists of skills: critical thinking and 
problem solving, collaboration across networks, agility and adaptability, initiative and entrepreneurialism, effective communication, accessing and analyzing information, and curiosity and imagination (Wagner, 2014). Many others add Information and Communication Technology literacy.

We may argue that STEM education in general and especially mathematics education appears to be the domains pre-eminently fit for fostering 21 st century skills. In fact, skills such as critical thinking, problem posing, problem solving, collaborating, and communicating have already been on the agenda of mathematics educators for a long time. These skills are seen as instrumental in problem-centered instructional approaches that recognize that knowledge is not transmitted and aim at supporting students in constructing mathematics. This evokes two questions, "What is new?" and "Why did this call for innovation not bring what one hoped for?" To answer the first question, we may note that the calls for reform of the past (National Council of Teachers of Mathematics, 1980) did not have their basis in concerns about the future, but in theories and beliefs about what it means to learn mathematics and about the value of applications. Analyzing mathematics education reform in the Netherlands, Gravemeijer, Bruin-Muurling, Kraemer and van Stiphout (2016) point to an inadequate translation of intentions into curriculum goals and the inclination of teachers and textbooks authors "to think of instruction in terms of individual tasks that have to be mastered by the students" (p. 26), a phenomenon they call task propensity. They add that the latter is reinforced by operational goal descriptions and corresponding tests consisting of sets of individual tasks. Often, mathematical processes or thinking skills are also mentioned in curriculum documents, but not assessed.

Another hurdle that research revealed was that adequate learning ecologies possess some demanding characteristics (see also Gravemeijer, 2014), such as specific classroom social norms (Yackel \& Cobb, 1996) and genuine mathematical argumentation (Forman, Larreamendy-Joerns, Stein \& Brown, 1998; Herbel-Eisenmann, 2002; Stein, Engle, Smith \& Hughes, 2008; Truxaw \& DeFranco, 2008; Yackel, 1997). Teachers will have to be able to orchestrate whole class discussions, asking deepening questions, and posing tasks that help students to reflect and build upon their current thinking. All in all, we may conclude that successful educational change aiming at 21 st century skills will require a fundamental change in curricula, tests, and instructional practices, which we (with Wagner, 2014) believe is only possible with a broad support of policy makers and the society as a whole. This, in turn, harkens back to the importance of a public awareness of the need to prepare our students for their future in the digital society. This discussion leads us to explore what goals should be the focus of mathematics education beyond those of general 21 st century skills.

\section{Mathematics-Specific Goals}

Even though 21st century skills dominate (public) discussions about education for the future, we consider the content that has to be taught at least as important, especially in the case of mathematics. In our view, mathematics education should prepare students for applying mathematics in all sorts of work- and everyday-life situations. In the following, we will primarily look at the use of mathematics with an eye on employability, as this is where we see the biggest impact of the digitalization of our society. To 
gain an understanding of what the demands of mathematics in reality are, we will take three different perspectives. (1) As mathematics at the workplace differs significantly from school mathematics, we will try to chart the characteristics of mathematics at the workplace, in order to get an image of what mathematical activity the students have to be prepared for. (2) To anticipate the demands of the 21 st century, we will take our starting point in the prospect that everybody will be working in a computerized environment. Here, we will take a more analytical approach when trying to identify the mathematical competencies that complement the work of computers. (3) Finally, we will speculate on how the increasing use of information technology will affect the mathematical topics that gain significance under influence of the use of information technology in order to identify what mathematical content will have to be pursued.

\section{Characteristics of Workplace Mathematics}

Many researchers of mathematics in the workplace have found that the mathematics people engage in outside of the school setting differs significantly from the character of school mathematics (Lave, 1988; Nunes, Schliemann \& Carraher, 1993; Saxe, 1988). Although the demands of the workplace have changed since those studies, current research continues to reveal the gap between workplace and school mathematics (FitzSimons, 2013; Wedege, 2002). We therefore find it expedient to explore the character of the workplace in order to push the envelope on what mathematics should look like for success in the future.

Informal Nature of Workplace Mathematics. For the past few decades, a body of work has focused on the mathematics of adults and workers in a variety of cultures. Examples of this type of analysis include the mathematics of carpenters (Millroy, 1991), pool builders (Zevenbergen, 1997), masons (Moreira \& Pardal, 2012), builders (Bessot, 1996), nurses (Hoyles, Noss \& Pozzi, 2001), and structural engineers (Gainsburg, 2007), to name only a few. A major finding from these studies is that the mathematics taught in school settings is typically not the mathematics people use to be successful in their workplace (Marr \& Hagston, 2007; Mills, 2012; Wedege, 2002). For example, nurses do not use conventional proportional reasoning strategies taught in school (e.g., cross multiplication) to determine appropriate ratios for administering medicine to patients. Rather, they use more efficient, informal strategies that are typical for their situation. In fact, one study showed that while a majority of nurses are unsuccessful on school-based proportion tests, they are $100 \%$ accurate when administering medicines in correct ratios using personally created strategies (Hoyles, Noss, Kent \& Bakker, 2013; Perlstein, Callison, White, Barnes \& Edwards, 1979).

Meaning of Context in the Workplace. Despite calls from many reports, research, and mathematics organizations to contextualize mathematics, many schools continue to present mathematics as abstract, decontextualized problems. In contrast, workplace mathematics research indicates that mathematics is not typically done outside of a context comprised of goals and purposes. For example, rarely can isolated incidences of decimal operations be found at the workplace. Rather, most calculations are performed across the domains of mathematics, such as algebra, number, and geometry, and are conducted as part of a contextualized problem (Wake \& Williams, 2001). Against this 
background, STEM educators recommend that mathematics be learned by presenting problems in realistic contexts such as biology, physics, engineering, etc. (e.g., Cox, Reynolds, Schunn \& Schuchardt, 2016). Two words of caution are warranted here. English (2016) notes that STEM research tends to place mathematics in the background, relegating it to support for STEM contexts rather than important in its own right. Secondly, contexts that are used in mathematics instruction tend to reflect contrived situations rather than those that are truly realistic and are rich sites for mathematizations. One noted exception is the work done by researchers from the Freudenthal Institute (Freudenthal, 1991; Gravemeijer, 2008).

Not only do workers use situated, informal mathematical strategies, but they also do not typically see themselves as "doing mathematics" in their work even though an outsider can find mathematics in an abundance of their activity (Mills, 2012; Nicol, 2002). Wake and Williams (2001) use Activity Theory to explain that workplace and school/college mathematics are different genres with overlap and specific boundaries. On the one hand, school mathematics is influenced by the formal, professional practices of mathematicians and the teachers that learned mathematics in that system. On the other hand, workplace mathematics is dominated by practical problems with culturally specific tools, practices, and discourse (Wake \& Williams, 2001). This observation leads directly into the next characteristic of workplace mathematics, the meaning of context in both genres.

Workplace Tools, Practices, and Discourse. Mathematical tools, practices, and discourse can be seen as shaped by the goals and problems encountered in the workplace (Magajna \& Monaghan, 2003). For example, Williams, Wake and Boreham (2001) present an analysis of the mathematics of workers at an industrialized chemical laboratory in which the employees effectively use noncanonical graphs that differ significantly from conventional graphs learned in college. Hoyles and Noss (Hoyles, Noss, Kent \& Bakker, 2010) coined the term "techno-mathematical literacies" (TmLs). TmLs are defined as idiosyncratic forms of mathematics that are shaped by workplace practices, tasks, and tools. The TmLs consist of a combination of mathematical knowledge and contextual knowledge.

Workers' unique use of tools is dominated by the purpose for which they are using it. School mathematical practices treat artifacts as conceptual tools rather than as the practical tools of the workplace (Jurdak \& Shahin, 2001). Wake and Williams (2001) suggest that the purpose of using tools in school settings is to pass an exam. Workers, in contrast, are motivated to use certain tools in order to complete very distinct objectives for customers. For example, school students interpret and reason with Cartesian graphs in very formal ways while workers at the chemistry lab construct them for their own efficiencies (such as having the smallest variable value to the right on the $\mathrm{x}$-axis).

Not only do the types of tools and activities with them differ in the workplace and school genres, but the practices do as well. Problem solving practices in both genres also differ significantly. We have already mentioned that workers use tools differently than students due to their overall objective of satisfying a boss or customer. In addition, workers often engage with complex, messy problems that can have multiple correct solutions. The aim, for them, is to find those solutions and work within the constraints of the situation to pick the most viable pathway (Brady, Eames \& Lesh, 2015). For example, the most efficient solution in an architectural design problem may not be the 
cheapest and the firm may lose the bid if presenting that to the customer. Therefore, certain tradeoffs must be considered when choosing a solution path. This differs from school mathematics in which teachers present neat problems with one correct solution. The goal for students is to find that solution in order to pass an exam. Additionally, the problems are presented by a teacher, whereas in the workplace problems are often created by the worker. To emphasize this point, engineers in Tosmur-Bayazit and Ubuz's study suggested changes in teaching methods such that instruction should not only be about solving equations correctly, but it should also focus on how to represent the key features of a real phenomenon (Tosmur-Bayazit \& Ubuz, 2013).

Discourse in the workplace differs radically from school settings as well. The meanings of certain mathematical symbols and words are negotiated in the activity setting of which workers or students are a part (Wake \& Williams, 2001). This means that the mathematical language and symbols that workers use may not carry the formal significance of those in school settings (recall the idiosyncratic use of the Cartesian plane by lab chemists).

Change over Time. Technological advances rapidly change the role of skilled and unskilled workers in the workplace. Planning functions in an organization were once the purview of management level workers; however, technology has taken over the work of many unskilled laborers requiring a different set of skills to be successful in the workplace (Wedege, 2002). The evolution of technological devices has fundamentally lessened the need to compute in the workplace and often workers do not recognize the necessity and presence of mathematics in their jobs. Technology has also relegated the mathematics to a black box, making the mathematics invisible to the worker (Williams \& Wake, 2007a). The globalization of the workplace now makes it possible for businesses to custom make products for clients all over the world. Thus, globalization has caused the practices of the workplace to shift from prototypical product creation (one size fits all) to using mathematical reasoning and critical thinking to customize products. With complex mathematics hidden in technological black boxes, it is imperative that the worker understands the mathematical calculations enough to create the input and interpret the output of the technology (Kent, Noss, Guile, Hoyles \& Bakker, 2007; Gainsburg, 2007). Employees must also be able to communicate the black box mathematics to their peers and bosses (Williams \& Wake, 2007b). Given the necessity of communicating the mathematics hidden within technological black boxes, it is not surprising that employers see communication and critical thinking as one of the most essential skills they seek in college graduates (Hoyles, Wolf, Kent \& Molyneux-Hodgson, 2002).

This sketch of the characteristics of mathematics at the workplace offers a background for a discussion on the goals of mathematics education. To identify goals for the future, however, we have to be more specific due to increased demands of the digital society. We turn now to a discussion of the mathematical competencies that are influenced by the computer age.

\section{Mathematical Competencies that Complement the Work of Computers}

If it is acknowledged that one of the goals of mathematics education is to prepare students for life and work, the aforementioned characteristics of the workplace will 
have to be taken into account in mathematics education. This idea is not new; it is reflected in calls for modeling and applications and for the use of authentic problem situations in education. Currently, the latter is one of the main spearheads of the STEM movement. The flipside of the coin, however, gets less attention, namely the character of the mathematics that is taught has to be adapted too. The mathematics learned in school has to allow for flexible use and adaptation. In relation to this, we may harken back to Freudenthal (1968) who, already in the 1960s, talked about teaching mathematics as to be useful. He argued that formal mathematics is generally applicable in theory, but only for experts with a high level of expertise, and generally not for the average student. We will return to this point later on.

First, we want to stress that when we consider mathematics education for the future, there is more to it than anticipating workplace characteristics. We are heading for a future where machines will do all mathematical calculations. Thus, the question arises, "What mathematics do we teach when computers do all mathematics?" (Wolfram, 2010). Wolfram (2010) tries to answer this question by analyzing what is involved in doing mathematics in the real world. He argues that this involves the following steps:

- Recognizing where mathematics is applicable

- Translating practical problems into mathematical problems

- Solving the mathematical problem

- Interpreting and evaluating the outcomes

He observes that, typically, only the third step is systematically addressed in mathematics education, and that this is exactly the step that is increasingly carried out by computers! In mathematics education, the attention will have to shift towards the other three steps. Moreover - as came clearly to the fore in the workplace studieswhen computers do the mathematical calculations, one has to understand the mathematics underlying those calculations.

We may merge the first, second, and the last step under the heading, "modeling \& applying," while separating "checking calculations" from interpreting and evaluating results. As we will substantiate later on, prioritizing checking calculations over executing standard procedures has significant consequences for the content and structure of the curriculum. This offers us three categories for discussing what mathematical competencies are required for the digital society: applying/modeling, understanding, and checking.

Applying/Modeling. Modeling and applications have been on the agenda of the International Community of Teachers of Mathematical Modelling and Applications (ICTMA) for a long time. However, modeling still gets little attention in everyday school practice. Research on modeling in mathematics education tends to focus more on the role of modeling in the service of learning and doing certain mathematical concepts (Gravemeijer, Lehrer, van Oers \& Verschaffel, 2002). However, the motivation for creating and interpreting models in the workplace is to mathematize a realistic situation for the purposes of answering a practical question, not to learn a mathematical idea. A notable exception in education is the work within the Models and Modeling Perspective group (Hamilton, Lesh, Lester \& Brilleslyper, 2008), which has produced one of the most elaborated instructional approaches aiming at fostering students' 
modeling skills, denoted as Model Eliciting Activities (MEAs). A Model Eliciting Activity is conceived as an authentic problem in a real-world situation, which requires the students to generate a model to interpret, explain, and make predictions about that situation in order to solve the problem. Those MEAs are also seen as a catalyst for STEM education; in this regard, Hamilton et al. (2008) especially point to the opportunities to connect mathematics and engineering.

We may expand this discussion of the differences between real-world problem solving in the digital society and school math on the basis of Brady et al. (2015). They make the following observations, in which much of the findings reported in the section on the workplace recur. People often work in groups in order to take advantage of the variety of expertise that people can bring to the table. When solving problems in reality, the needs of an actual client determine the criteria the solution has to meet. At the same time, however, the qualities that the client finds important may have to be further specified or operationalized. Working for a definite client often also determines what measurements are available, while data sources may have to be interpreted or created first. It is also typical in real-world problems that the solutions have to address uncertain or changing conditions and tradeoffs.

To identify the competencies that are needed for modeling real-life problems, we may look at the PISA 2015 Mathematics framework (OECD, 2016). This framework contains the same steps Wolfram (2010) uses to describe the process of modeling realworld problems and which can be found in most models of solving problems in reality (Verschaffel, Greer \& De Corte, 2000; Vorhölter, Kaiser \& Ferri, 2014). Next to mathematical knowledge, concepts, and skills, the framework references a variety of mathematical capabilities, which are especially relevant for modeling. These competencies reflect two main activities we placed in the category applying and modeling, the transition from reality to mathematics, and the transition back from mathematics to reality. In connection to the transition from reality to mathematics, the framework mentions capabilities, such as decoding and interpreting information, structuring and conceptualizing the problem situation, making inferences and assumptions, and formulating a model. For the reverse activity, they mention capacities, such as summarizing and presenting results and providing explanation or justification and interpreting or evaluating the mathematical outcome. In addition, they also refer to using graphs, tables, diagrams, pictures, equations, and formulae. Mark that, as we noted above, modeling involves using the mathematical concepts and procedures, which modelers have to connect with applications, which often is a problem with school mathematics. Adopting modeling and applying as goals therefore has implications for the character of the mathematics being taught. We will elaborate on this issue further when discussing the category "understanding."

There is, however, one more point we want to raise: Not all workers will be active modelers. In many cases, they will be using models invented by others. In this respect, we would argue that the notion of Techno-mathematical Literacies generally points to the need for understanding the hidden, idiosyncratic, mathematics that is shaped by tools and the practices developed by others. In addition, it may be more common that workers have to use or adapt the results of other people's modeling activity. Oldenburg (2011), for instance, notes that it is rather common in the workplace for individuals to encounter a problem and pick from an array of already produced models, although it may happen that the prestructured model needs to be altered and thus can evolve as it is 
used in a number of different situations. From Oldenburg's (2011) point of view, the arrow from the real world to models should point backwards as well. Thus, both types of modeling need to be considered. We may further add that next to being involved in modeling or using models, many people will be using the results of the modeling work carried out by others. This too will have an impact on the modeling competencies that are needed.

We may close this section with a brief discussion of the hurdles that may occur in instruction. Often, teachers see real-world contexts only as motivational tools and do little justice to those contexts. Many teachers quickly transform the contextual problem into a mathematical problem, foregrounding the calculation that needs to be performed. In relation to this, Thompson, Philipp, Thompson and Boyd (1994) speak of a calculational orientation, which they contrast with a conceptual orientation. Teachers with a calculational orientation tend to disregard both the context and the manner in which the calculations arise from understanding the context. They primarily speak in terms of numbers and operations, focus on identifying and performing procedures, and aim at producing numerical solutions. Teachers with a conceptual orientation, in contrast, strive for conceptual coherence and focus on supporting students in coming to grips with the role and meaning of the numerical values in the situation and how this translates in numerical operations. An implication of this work is that a conceptual orientation to mathematics is more conducive to understanding mathematical modeling.

Understanding. Workplaces have not only become increasingly highly automated, but companies are also trying to respond flexibly to customer needs. The consequence thereof is that employees at many levels have to understand what is going on in order to be able to communicate with both colleagues and customers. The thesis that people need to understand the mathematics that is involved in the work machines do is corroborated by observations of technology-rich workplaces (Kent et al., 2007; Gainsburg, 2007).

We saw that workplace knowledge usually is idiosyncratic and bound to specific contexts and tools. In relation to this, we already referred to the notion of TmLs (Hoyles $\&$ Noss, 2003). These TmLs consist of a combination of mathematical knowledge and contextual knowledge. This begs the question: What form of mathematical knowledge might best prepare students for appropriating TmLs? It seems self-evident that understanding the underlying concepts will be more useful than mastery of rigid procedures. Note that this does not alter the fact that some level of procedural proficiency will be needed as well, if only to develop those concepts. We may argue, however, that, with the increased availability of technology, this need for mastery of routine skills diminishes. This creates room for working on the conceptual mathematical understanding that is needed to grasp the mathematics that is hidden in the digital tools that are abundant in our technological society. When speaking of conceptual understanding, we may refer to the well-known distinction Skemp (1978) makes between instrumental and relational understanding. We may illuminate the difference by taking the arithmetical mean as example. Understanding the mean instrumentally pertains to understanding the procedure and the recipe: Add the individual measures and divide by the number of measures. Relational understanding concerns the conceptual meaning. The mean refers to a value that represents the measures in the data set in a valid manner. As a metaphor, we may think of "the average man." The underlying conception is that of individual 
distances between the mean and the other data values that add up to zero. Conceptual understanding of the mean would also encompass understanding the sensitivity of the mean to an asymmetric distribution or extreme values.

Next to the relational understanding which has to be aimed for, we will have to consider what level of understanding is needed and for whom. We might conjecture that, in many cases, some kind of global, generic, understanding will be sufficient. In relation to this, we may refer to the work of Kaput $(1994,1997)$, who in the 1990s brought attention to the fact that increasing computerization created the need for teaching calculus to a much bigger part of the population. He argued that only $10 \%$ of students gained access to calculus, even though a much larger part of the population needed to be knowledgeable of the ideas and techniques of calculus. In relation to this, he called for, "democratizing access to the mathematics of change and variation" (Vahey, Lara-Meloy \& Knudsen, 2009, p. 417). To cater to the other $90 \%$ of the students, we would have to focus on "the key underlying ideas of rate of change, accumulation, the connections between variable rates and accumulation, and approximation" (Kaput, 1997, p. 733). In his view, this can be reached by deploying the dynamic representations that computers allow for, of which the work on SimCalc (Roschelle et. al., 2010) is an example. In conclusion, we may argue that Kaput's (1997) thesis will hold for many other topics nowadays; in the digital society, people need to understand the key ideas that underlay the mathematics that is used by machines. This resonates in the work of Hoyles and Noss cum suis (Hoyles, Noss, Kent \& Bakker, 2010), who also advocate conceptual understanding of the mathematics involved and who design artifacts - such as computer tools - to support workers in developing this understanding.

This brings us to the role of computer tools that are tailor-made to support the development of coming to grips with the key ideas in specific areas. Next to the computer tools developed by the group of Hoyles cum suis (e.g. Bakker, Kent, Noss \& Hoyles, 2009), and the Simcalc software developed by Kaput and associates, we may refer to the computer tools developed in design experiments some of us have been involved in, e.g., on Data Analysis (Cobb, McClain, \& Gravemeijer, 2003), calculus (de Beer, Gravemeijer \& van Eijck, 2015; Doorman \& Gravemeijer, 2009), and functions (Doorman, Drijvers, Gravemeijer, Boon \& Reed, 2012). In our view, the goal of coming to grips with key ideas, and the potential of tailor-made educational computer tools to reach this goal, has to be taken into account when considering which subject matter might be feasible for the majority of students.

Checking. An important aspect of evaluating the outcome of a computer-generated answer to some problem concerns the question of how the results fit the problem context and whether the solution is feasible in that context. Another aspect concerns the mathematical correctness of the computed result. We may start by noting that the idea is not that users of computerized apparatus should repeat the calculations by hand. Instead, we want them to be able to check whether the result seems plausible. In our view, this has profound implications for the mathematics curriculum. We may illustrate this by checking an answer to an arithmetical calculation. Here, one might do some "global arithmetic" by adjusting the numbers to simplify the calculation and using this modified calculation to judge if the answer is reasonable. Elaborating on this example, we want to elucidate that this requires a different kind of arithmetic than is currently taught. 
The basis for global arithmetic lays in flexible reasoning with number relations, working with zeros and arithmetical properties (Gravemeijer, 2015). Let us take $78 \times 1261$ as an example. This may be approximated by $75 \times 1200$, using $12=4 \times 3$, thus $1200=4 \times 300$, and $75 \times 4=300$ and $300 \times 300$ is 90,000 , or by $80 \times 1250$, and using $8 \times 125=1000$ and $1000 \times 100=100,000$. Gravemeijer $(2015)$ argues that the use of number relations is key here; when the problem solver uses number relations that are familiar and ready to hand, he or she can be confident that the approximation is valid. Following this line of reasoning, we may conclude that we have to support students in developing number relations that can be used in a variety of calculation situations (e.g., multiples of $25,75,125$, etc., and the links of those numbers with decimals, fractions, and percentages). Ideally, students would develop networks of number relations, which they can connect flexibly, which in turn might strengthen their confidence in the number relations that are familiar to them. We may add that flexible use of number relations also implies the use of arithmetical properties - such as the commutative, associative, and distributive property-preparing students for algebra.

We may further note that checking mathematical correctness encompasses more than global recalculation. Mathematical correctness may also concern the adequacy of the mathematical procedures, approximations, or generalizations. In relation, we may point to Levitin (2016), who investigated how outsiders can judge the validity and credibility of the results of statistical procedures carried out by others.

The above arithmetic example shows that a curriculum aiming at fostering the arithmetical skills involved in checking computer output will differ significantly from the conventional curriculum aiming at quickly producing precise answers. The same holds for statistics, especially because efforts to help students gain experience with doing statistics often concern watered down experiments that just do not meet the requirements that "statistics consumers" should be critical of (Levitin, 2016).

\section{Mathematical Content}

The abundant use of digital technology does not only raise the need for skills that complement what computers (can) do, but it also influences what mathematics is or becomes relevant in our society. A clear example is that of statistics. A large part of the information in our society is statistical information, and we may point to "big data" as a growing field, as a result of the unprecedented access to data and computer power. People therefore need some basic understanding of statistical processing and analyses, which has been called statistical literacy (Gal, 2002). Another topic that gains new significance is space-geometry, as a consequence of the growing role of $3 \mathrm{D}$ imaging and $3 \mathrm{D}$ printing. Among the most relevant topics, Hoyles et al. (2010) mention measurement, data collection, variables and co-variation, reading and interpreting data, graphs, and charts. Brady et al. (2015) also point to the importance of covariation and functions, which they see as building blocks for modeling aspects of systems.

In a more general sense, it may be argued that the software embedded in computerized apparatus will have the character of mathematical models of reality, which will consist of systems of interconnected mathematical relations. Thus, individuals will need 
an understanding of variables, co-variation, and functions. In a similar manner, we may argue that working with computers requires that phenomena from reality are translated into numerical quantities. This points to the need for a deep understanding of the process of quantifying reality, including the awareness that quantifying reality goes with a reduction of information, and that quantification might even result in meaningless numbers in some cases. Understanding the process of quantifying reality requires a broad understanding of measuring and measures comprising notions of uncertainty and repeated measurement, mean, and measurement error. Similarly, concepts such as data creation and sampling come to the fore.

A specific point concerns the ability to work with computer tools. Next to the computerization of all sorts of apparatus, the twenty-first century has also brought a variety of computer tools which are available in the form of handheld calculators, spreadsheets, computer algebra systems, graphing tools, and so forth. This means that students will have to learn to work with these types of computer tools. Often, this will not only concern technical instructions - as in the case of spreadsheets - but may also involve complex processes. As an example of such a process, we may refer to what researchers of "computer algebra systems" (CAS) call "instrumentation" (Drijvers \& van Herwaarden, 2000). The user of a CAS has to develop an instrumentation scheme, which not only consists of a series of actions but also involves mathematical objects and strategies. With other computer tools, a similar interconnectedness with learning mathematics may be expected.

\section{Mathematics in Everyday Life}

When considering the goals of mathematics for the future, we also have to think of the use of mathematics in everyday life. Here too, the demands in terms of "the knowledge and skills required to effectively manage and respond to the mathematical demands of diverse situations" (Gal, Groenestijn, M van, Manly, Schmitt \& Tout, 2003, p. 4) grow as a consequence of the increasing digitalization of our society. In relation to this, the terms numeracy and quantitative literacy are used, both with varying and overlapping meanings. Typically, those concepts do not discriminate between work and everyday life. Still, the main orientation appears to be towards everyday life and citizenship. In relation to the latter, Steen (2001) points to the importance of quantitative literacy for democratic discourse and civic decision-making, which may involve quantitative information, such as interest-rate cuts by the Federal Reserve, changes in gasoline prices, trends in student test scores, election results, and risks of dying from colon cancer.

Studies in numeracy, as well as mathematical literacy, are of significance for our investigation, as they offer reference points for what all adults need to thrive in the twenty-first century society. With this in mind, we will briefly describe the topics that are mentioned in the ALL Numeracy Framework (Gal et al., 2003). Dealing with quantity and number requires not only common measures, such as length area, weight, time, money, etc., but also measures such as humidity, air pressure, population growth rates, and profits of companies. In the context of dimension and shape, one has to grasp the dimensions of real objects and abstract things and visualizations thereof (maps, projections, etc.). Dealing with the world mathematically further asks for recognizing, interpreting, and creating patterns, functions, and relationships, while using tools such as tables, graphs, symbols, and words, functions, and relationships between variables 
are considered essential for understanding (basic) economic, political, and social analyses. The pervasive role of statistics in the digital society asks for the ability to deal with data and chance, encompassing big ideas such as variability, sampling, error, prediction, and the distinction between signal and noise. Related aspects are data collection and data displays (graphs, frequency tables, and pie charts). The ALL framework entails change as a separate category, which includes how organisms grow, populations vary, prices fluctuate, and traveling speed may vary. Also rates of change may need attention, as in the context of compound interest, for instance.

Not surprisingly, there is a large overlap with what is required in the workplace, although there seems to be an even stronger priority on mathematical contexts used in the ALL framework. Contextual problems are often the core of adult education, while the participants are supported in preserving the connection with the problem context and the solution in their reasoning. As another difference, we may point out that the overriding concern in the literature on adult life skills concerns self-reliance and self-confidence.

\section{Considerations}

Before concluding this stocktaking, we want to reiterate that the objective of this paper is not to produce an exhaustive inventory of goals and societal demands. The aim of this reconnaissance is to create a basis for discussion, a discussion which, in our view, is long overdue. We will therefore briefly address some topics that have been underexposed in our exploration. A self-evident issue here is the role of more formal mathematics. Our focus has mainly been on the practical value of mathematics in the world outside school. The goal of mathematics education, however, is also to prepare students for further education to which we may add the importance of understanding and appreciating mathematics as a goal in and of itself. Thus, a proper balance will have to be sought.

This does not necessarily entail an opposition; formal abstract mathematics may also support practical applications. We may illustrate this with number theory. Number theory concerns number systems, properties and relations of numbers, special numbers (triangular numbers, square numbers, perfect numbers, and prime numbers), divisibility, etc. These are issues that are relevant in the digital society in connection to modern phenomena like coding, hacking, etc. Further, it can be taught on a very elementary level; number theory is very suitable to let children explore, experiment, and ask themselves questions. This topic is also easy to link to history of mathematics and to our human heritage, which in itself can be seen as a goal of mathematics education. Finally, it may be noted that prime numbers offer unsolved problems in mathematics and are thus related to advanced mathematics.

The need to prepare students both for further education and for life means that a balance has to be found with the goal of preparing students for life outside school. This encompasses issues such as canonical versus noncanonical forms of mathematics, understanding mathematics on a generic level and coming to grips to a rigorous underpinning, and the tension between grasping mathematics in contexts or on a formal level.

\section{Topics that Lose Relevance}

While discussing topics that need to be incorporated in the curriculum, we have circumvented the tricky issue of what topics should receive less attention. One of the 
mathematics educators who put this topic on the agenda is Zalman Usiskin. He makes the following arguments. We continue to see what he calls "phony traditional word problems" in textbooks and instruction, even though realistic settings and modeling are important for future mathematics learning (Usiskin, 1980, 2007). Traditional word problems must be replaced by problems situated in realistic settings with real goals and implications. Further, he goes on to say, since computer algebra systems on handheld calculators can conduct trinomial factoring efficiently and most quadratics observed in realistic settings are solved by the quadratic formula, he advocates that manual factoring be deleted from the curriculum (Usiskin, 2004). Finally, in his view, the role of geometric proof should be in question as well (Usiskin, 2007). He argues that proofs are fundamental to understanding how all mathematics works, not just in geometry, so we should leave some proving in the curriculum. However, he notes that there are multiple dynamic geometry tools that allow a different type of mathematical exploration and proof that should be integrated into instruction. Mathematics educators and policymakers should consider equally what mathematics calculations are important for the curriculum and what abstract mathematics is essential.

\section{Discussion}

While acknowledging the broad endeavor of developing STEM education for the future, we argued at the start of this article that the special position of mathematics in the digitized society merited an independent analysis of the goals of mathematics education for the future. We found that the question of how mathematics education might prepare students for the society of the future generated a host of topics for discussion, a discussion which, in our view, has been long overdue. To spark this discussion, we will close by presenting a list of propositions that are partly based on research and literature reviewed above, but mainly argumentative.

- 21st Century skills have to be adopted as goals of mathematics education for the future, while taking into account that specific attention will have to be given to mathematics specific forms of argumentation and communication.

- Preparing students for mathematics in the workplace is one of the goals of mathematics education. Issues that are at play here concern the use of tasks that resemble authentic workplace problems, mathematics that is taught as to be useful, and balancing canonical and noncanonical forms of mathematics.

- 21 st Century digitalization of society requires a focus on mathematical competencies that complement the work of computers. This points to modeling and applications as goals for mathematics education. This overlaps with the aforementioned point, with a note that, apart from gaining experience with authentic-like problems, partial skills may also become the focus of attention.

- An important element of competencies that complement the work of computers concerns understanding the mathematics underlying the mathematical work computers take over. What is needed here is conceptual understanding on a generic level; students have to come to grips with the key ideas underlying the relevant mathematics. This begs the question of how to attain such understanding. More specifically, how much, and which, routine skills are needed to reach more 
sophisticated goals? And how can tailor-made software applications facilitate this process?

- Choosing for 21 st century skills and high-level conceptual understanding requires a significant effort in teacher professionalization, curriculum design, and test design. We have to embed this in a broad public support for, and awareness of, the need to prepare students for the digital age.

- General education has to lay the foundation for a wide variety of levels and types of work. We would argue that the focus has to be on foundational education. Digitalization especially affects jobs at the middle and the bottom of the labor market and to make sure that students that may leave school at an early age get a sound preparation. We may argue that this basis has to be general. Further education may take care of specialization, but more importantly, the world of work changes so fast that specific skills may quickly lose their significance.

- Even though there is a large overlap between preparation for work or for everyday life, the latter should get special attention. Important goals here are self-reliance and self-confidence when dealing with mathematics in everyday life and active citizenship. In relation to this, we want to emphasize the importance of one of the key 21 st century skills: critical thinking.

- Finally, all attention for mathematics that has practical relevance outside school should not marginalize the importance of preparation for further education, or the value of mathematics as part of our cultural inheritance.

These propositions were motivated by decades of past research on the mathematics of humans in the workplace and school as well as by reflecting on the growing need to change instruction due to globalization and digitalization. We are not currently preparing students for the demands of the twenty-first century workplace and world. Despite requests from businesses, educational organizations, and researchers, mathematics instruction has not changed to keep up with the needs of society. In this paper, we have presented the need for more formal efforts to update mathematics education in terms of both content and technique. Our discussion is intended to spark a more global conversation and, perhaps a more organized action, on mathematics education for the future.

Open Access This article is distributed under the terms of the Creative Commons Attribution 4.0 International License (http://creativecommons.org/licenses/by/4.0/), which permits unrestricted use, distribution, and reproduction in any medium, provided you give appropriate credit to the original author(s) and the source, provide a link to the Creative Commons license, and indicate if changes were made.

\section{References}

Bakker, A., Kent, P., Noss, R. \& Hoyles, C. (2009). Alternative representations of statistical measures in computer tools to promote communication between employees in automotive manufacturing. Technology Innovations in Statistics Education, 3(2), 1-31.

Bessot, A. (1996). Geometry and work-Examples from the building industry. In A. Bessot \& J. Ridgeway (Eds.), Education for mathematics in the workplace (pp. 143-158). Dordrecht, the Netherlands: Kluwer.

Brady, C., Eames, C. \& Lesh, D. (2015). Connecting real-world and in-school problem-solving experiences. Quadrante, 24(2), 5-36. 
Brynjolfsson, E., \& McAfee, A. (2014). The second machine age: Work, progress, and prosperity in a time of brilliant technologies. New York, NY: WW Norton \& Company.

Cobb, P., McClain, K., \& Gravemeijer, K. (2003). Learning about statistical covariation. Cognition and Instruction, 21(1), 1-78.

Cox, C., Reynolds, B., Schunn, C. \& Schuchardt, A. (2016). Using mathematics and engineering to solve problems in secondary level biology. Journal of STEM Education, 17(1), 22-30.

de Beer, H., Gravemeijer, K. \& van Eijck, M. (2015). Discrete and continuous reasoning about change in primary school classrooms. ZDM, 47(6), 981-996.

Doorman, M., Drijvers, P., Gravemeijer, K., Boon, P. \& Reed, H. (2012). Tool use and the development of the function concept: From repeated calculations to functional thinking. International Journal of Science and Mathematics Education, 10(6), 1243-1267.

Doorman, L. M. \& Gravemeijer, K. P. E. (2009). Emergent modeling: Discrete graphs to support the understanding of change and velocity. ZDM, 41(1-2), 199-211.

Drijvers, P. \& van Herwaarden, O. (2000). Instrumentation of ICT-tools: The case of algebra in a computer algebra environment. The International Journal for Technology in Mathematics Education, 7(4), 255-75.

English, L. D. (2015). STEM: Challenges and opportunities for mathematics education. In K. Beswick, T. Muir \& J. Wells (Eds.), Proceedings of 39th Psychology of Mathematics Education conference (Vol. 1, pp. 3-18). Hobart, Australia: PME.

English, L. (2016). STEM education K-12: Perspectives on integration. International Journal of STEM Education. doi:10.1186/s40594-016-0036-1.

FitzSimons, G. (2013). Doing mathematics in the workplace. A brief review of selected literature. Adults Learning Mathematics: An International Journal, 8(1), 7-19.

Forman, E. A., Larreamendy-Joerns, J., Stein, M. K. \& Brown, C. A. (1998). You're going to want to find out which and prove it: Collective argumentation in a mathematics classroom. Learning and Instruction, 8(6), 527-548.

Freudenthal, H. (1968). Why to teach mathematics so as to be useful. Educational Studies in Mathematics, $1(1), 3-8$.

Freudenthal, H. (1991). Revisiting mathematics education. Dordrecht, the Netherlands: Kluwer Academic Publishers.

Frey, C. B., \& Osborne, M. A. (2013). The future of employment: How susceptible are jobs to computerization. Retrieved on September 72013 from http://www.oxfordmartin.ox.ac.uk/downloads/academic/The Future_of_Employment.pdf.

Friedman, T. L. (2005). The world is flat: A brief history of the twenty-first century. London: Macmillan.

Gainsburg, J. (2007). The mathematical disposition of structural engineers. Journal for Research in Mathematics Education, 38(5), 477-506.

Gal, I. (2002). Adults' statistical literacy: Meanings, components, responsibilities. International Statistical Review, 70(1), 1-25.

Gal, I., Groenestijn, M van, Manly, M., Schmitt, M. J., \& Tout, D. (2003). Adult numeracy and its assessment in the ALL survey: A conceptual framework and pilot results. Ottawa, Canada: Statistics - Canada. Retrieved on September 202016 from: www.ets.org/all.

Gravemeijer, K. (2008). RME theory and mathematics teacher education. In D. Tirosh \& T. Wood (Eds.), International handbook of mathematics teacher education: Knowledge and beliefs in mathematics teaching and teaching development (Vol.1, pp. 283-302). Rotterdam, the Netherlands: Sense Publishers.

Gravemeijer, K. P. (2014). Transforming mathematics education: The role of textbooks and teachers. In Transforming Mathematics Instruction (pp. 153-172). Cham, Switzerland: Springer International Publishing.

Gravemeijer, K. (2015). Mathematics with prospect, primary mathematics education that prepares students for the society of the 21st century. Volgens Bartjens, 34(4), 4-7.

Gravemeijer, K., Bruin-Muurling, G., Kraemer, J. M. \& van Stiphout, I. (2016). Shortcomings of mathematics education reform in The Netherlands: a paradigm case? Mathematical Thinking and Learning, 18(1), 2544.

Gravemeijer, K., Lehrer, R., van Oers, B. \& Verschaffel, L. (2002). Symbolizing, modeling and tool use in mathematics education. Dordrecht, the Netherlands: Kluwer Academic Publishers.

Hamilton, E., Lesh, R., Lester, F. R. A. N. K. \& Brilleslyper, M. (2008). Model-eliciting activities (MEAs) as a bridge between engineering education research and mathematics education research. Advances in Engineering Education, 1(2), 1-25.

Herbel-Eisenmann, B. (2002). Using student contributions and multiple representations to develop mathematical language. Mathematics Teaching in the Middle School, 8, 100-105. 
Hoyles, C., \& Noss, R. (2003). What can digital technologies take from and bring to research in mathematics education?. In A.J. Bishop, M.A. Clements, C. Keitel, J. Kilpatrick and F.K.S. Leung (Eds.), Second international handbook of mathematics education (pp. 323-349). Dordrecht, the Netherlands: Springer.

Hoyles, C., Noss, R., Kent, P., \& Bakker, A. (2010). Improving mathematics at work: The need for technomathematical literacies. London, UK: Routledge.

Hoyles, C., Noss, R., Kent, P., \& Bakker, A. (2013). Mathematics in the workplace: Issues and challenges. In: A. Damlamian, J. F. Rodrigues, \& R. Strässer (Eds.), Educational interfaces between mathematics and industry: Report on an ICMI-ICIAM study (Vol 16). (pp. 43-50). Dordrecht, The Netherlands: Springer Science \& Business Media.

Hoyles, C., Noss, R. \& Pozzi, S. (2001). Proportional reasoning in nursing practice. Journal for Research in Mathematics Education, 32(1), 4-27.

Hoyles, C., Wolf, A., Kent, P., \& Molyneux-Hodgson, S. (2002). Mathematical skills in the workplace. Retrieved from http://www.ioe.ac.uk/tlrp/technomaths/skills2002/.

Jurdak, M. \& Shahin, I. (2001). Problem solving activity in the workplace and the school: The case of constructing solids. Educational Studies in Mathematics, 47(1), 297-315.

Kaput, J. (1994). Democratizing access to calculus: New routes to old roots. In A. Schoenfeld (Ed.), Mathematical thinking and problem-solving (pp. 77-156). Hillsdale, MI: Lawrence Erlbaum.

Kaput, J. (1997). Rethinking calculus: Learning and thinking. The American Mathematical Monthly, 104(8), $731-737$.

Keeler, S. P. \& Grandine, T. A. (2013). Getting math off the ground. In A. Damlain, J. Rodrigues \& R. Strasser (Eds.), Educational interfaces between mathematics and industry. Report on an ICMI-ICAM Study. Cham, Switzerland: Springer.

Kent, P., Noss, R., Guile, D., Hoyles, C. \& Bakker, A. (2007). Characterizing the use of mathematical knowledge in boundary-crossing situations at work. Mind, Culture, and Activity, 14(1-2), 64-82.

Lave, J. (1988). Cognition in practice: Mind, mathematics, and culture in everyday life. Cambridge, UK: Cambridge University Press.

Levitin, D. (2016). A field guide to lies and statistics. A neuroscientist on how to make sense of a complex world. London, UK: Viking.

Levy, F., \& Murnane, R. J. (2012). The new division of labor: How computers are creating the next job market. Princeton, NJ: Princeton University Press.

Magajna, Z. \& Monaghan, J. (2003). Advanced mathematical thinking in a technological workplace. Educational Studies in Mathematics, 52(2), 101-122.

Marr, B., \& Hagston, J. (2007). Thinking beyond numbers: Learning numeracy for the future workplace. NCSVR, Australia. Retrieved on September 242016 from http:/www.ncver.edu.au/publications/1795.html.

Millroy, W. L. (1991). An ethnographic study of the mathematical ideas of a group of carpenters. Learning and Individual Differences, 3(1), 1-25.

Mills, K. (2012). Some correspondences and disjunctions between school mathematics and the mathematical needs of apprentice toolmakers: A New Zealand Perspective. In: A. Hector-Mason \& D. Coben (Eds.), Proceedings of the 19th International Conference of Adult Learning Mathematics-A Research Forum (pp. 69-83), Auckland, New Zealand.

Moore, G. E. (1965). Cramming more components onto integrated circuits. Electronics, 38(8), $114-117$. Retrieved from https://drive.google.com/file/d/0By83v5TWkGjvQkpBcXJKT1I1TTA/view.

Moreira, D. \& Pardal, E. (2012). Mathematics in masons' workplace. Adults Learning Mathematics: An International Journal, 7(1), 32-48.

National Council of Teachers of Mathematics (1980). An agenda for action: Recommendations for school mathematics of the 1980s. Reston, VA: The Council.

Nicol, C. (2002). Where's the math? Prospective teachers visit the workplace. Educational Studies in Mathematics, 50(3), 289-309.

Nunes, T., Schliemann, T. \& Carraher, D. (1993). Street mathematics and school mathematics. Cambridge, UK: Cambridge University Press.

Organization for Economic Co-operation and Development (2016). PISA 2015 Mathematics Framework. In PISA 2015 Assessment and Analytical Framework: Science, Reading, Mathematics and Financial Literacy. Paris, France: OECD Publishing. doi:10.1787/9789264255425-5-en.

Oldenburg, R. (2011). Some thoughts on mathematics in the workplace and in school. For the Learning of Mathematics, 31(1), 28-30.

Partnership for 21st century skills (2015). P21 Framework definitions, Retrieved on December 202016 from http://www.p21.org/storage/documents/docs/P21_Framework_Definitions_New_Logo_2015.pdf.

Perlstein, P., Callison, C., White, M., Barnes, B. \& Edwards, N. (1979). Errors in drug computations during newborn intensive care. American Journal of Diseases of Children, 133(4), 376-379. 
Roschelle, J., Shechtman, N., Tatar, D., Hegedus, S., Hopkins, B., Empson, S., Gallagher, L. P. (2010). Integration of technology, curriculum, and professional development for advancing middle school mathematics three large-scale studies. American Educational Research Journal, 47(4), 833-878.

Saxe, G. (1988). Candy selling and math learning. Educational Researcher, 17(6), 14-21.

Skemp, R. R. (1978). Faux Amis. The Arithmetic Teacher, 26(3), 9-15.

Steen, L. A. (2001). Quantitative literacy. Education Week, 21(1), 58.

Stein, M. K., Engle, R. A., Smith, M. S. \& Hughes, E. K. (2008). Orchestrating productive mathematical discussions: Five practices for helping teachers move beyond show and tell. Mathematical Thinking and Learning, 10(4), 313-340.

Thompson, A., Philipp, R., Thompson, P. \& Boyd, B. (1994). Calculational and conceptual orientations in teaching mathematics. In D. Aichele \& A. Coxford (Eds.), Professional development for teachers of mathematics, 1994 yearbook of the national council of teachers of mathematics (pp. 79-92). Reston, VA: National Council of Teachers of Mathematics.

Tosmur-Bayazit, N. \& Ubuz, B. (2013). Practicing engineers' perspective on mathematics and mathematics education in college. Journal of STEM Education, 14(3), 34-39.

Truxaw, M. \& DeFranco, T. (2008). Mapping mathematics classroom discourse and its implications for models of teaching. Journal for Research in Mathematics Education, 39(5), 489-525.

Usiskin, Z. (1980). What should not be in the algebra and geometry curricula of average college-bound students? Mathematics Teacher, 73(6), 413-424.

Usiskin, A. (2004). A K-12 Mathematics curriculum with CAS: What is it and what would it take to get it? In W. Yang, S. Chu, T. de Alwis \& K. Ang (Eds.), Proceedings of the 9th Asian technology conference in mathematics (pp. 5-16). Blacksburg, VA: ATCM, Inc.

Usiskin, Z. (2007). What should not be in the algebra and geometry curricula of average college-bound students? A retrospective after a quarter century. Mathematics Teacher, 100, 78-79.

Vahey, P., Lara-Meloy, T. \& Knudsen, J. (2009). Meeting the needs of diverse student populations: Findings from scaling up SIMCALC project. In S. L. Swars, D. W. Stinson \& S. Lemons-Smith (Eds.), Proceedings of the 31st annual meeting of the North American Chapter of the International Group for the Psychology of Mathematics Education. Atlanta, GA: Georgia State University.

Verschaffel, L., Greer, B. \& De Corte, E. (2000). Making sense of word problems. Lisse, the Netherlands: Swets and Zeitlinger.

Voogt, J. \& Pareja, R. N. (2010). 21st century skills. Enschede, the Netherlands: Universiteit Twente.

Vorhölter, K., Kaiser, G., \& Ferri, R. B. (2014). Modelling in mathematics classroom instruction: An innovative approach for transforming mathematics education. In Y. Li, E. Silver, \& S. Li (Eds.), Transforming mathematics instruction (pp. 21-36). Cham, Switzerland: Springer International Publishing.

Wagner, T. (2014). The global achievement gap: Updated edition. New York, NY: Perseus Books Group.

Wake, G. D., \& Williams, J. S. (2001). Using College mathematics in understanding workplace practice. Summative report of research project funded by the Leverhulme Trust. Manchester, UK: Manchester University.

Wedege, T. (2002). Numeracy as a basic qualification in semi-skilled jobs. For the Learning of Mathematics, $22(3), 23-28$.

Williams, J. \& Wake, G. (2007a). Metaphors and models in translation between college and workplace mathematics. Educational Studies in Mathematics, 64(3), 345-371.

Williams, J. \& Wake, G. (2007b). Black boxes in workplace mathematics. Educational Studies in Mathematics, 64(3), 317-343.

Williams, J., Wake, G. \& Boreham, N. (2001). College mathematics and workplace practice: An activity theory perspective. Research in Mathematics Education, 3(1), 69-84.

Wolfram, C. (2010). Teaching kids real math with computers. Youtube, uploaded by TedTalks, 15 November 2010, https://www.youtube.com/watch?v=600VlfAUPJg.

Wolfram, C. (2014). The UK needs a revolution in the way maths is taught. Here's why... The Guardian, Sunday 23 February 2014; downloaded from http://www.theguardian.com/education/2014/feb/23/mathsteaching-revolution-needed-conrad-wolfram.

Yackel, E. (1997). Explanation as an interactive accomplishment: A case study of one second-grade mathematics classroom. Paper presented at the annual meeting of the American Educational Research Association. Chicago, Illinois.

Yackel, E. \& Cobb, P. (1996). Sociomathematical norms, argumentation, and autonomy in mathematics. Journal for Research in Mathematics Education, 27(4), 458-477.

Zevenbergen, R. (1997). Situated numeracy: A case study of pool builders. In N. Scott \& H. Hoolingsworth (Eds.), Mathematics: Creating the future (pp. 89-94). Melbourne, Australia: Australian Association of Mathematics Teachers. 